www.jmscr.igmpublication.org

Index Copernicus Value: 79.54

ISSN (e)-2347-176x ISSN (p) 2455-0450

crossref DOI: https://dx.doi.org/10.18535/jmscr/v7i5.113

Journal Of Medical Science And Clinical Research

IGM Publication

An Official Publication of IGM Publication

\title{
Spectrum of Foeto-maternal outcome in Jaundice with Pregnancy: An Insight
}

\author{
Authors \\ Dr Ritu Khatuja ${ }^{1}$, Dr Chhavi ${ }^{2}$, Dr Mini ${ }^{3}$, Dr N Sarda ${ }^{4}$ \\ ${ }^{1}$ Assistant Professor, Department of OBG, DR BSA Medical College \& Hospital, Rohini, Delhi \\ ${ }^{2}$ Senior Resident, Department of OBG, DR BSA Medical College \& Hospital, Rohini, Delhi \\ ${ }^{3}$ Postgraduate, Department of OBG, DR BSA Medical College \& Hospital, Rohini, Delhi \\ ${ }^{4}$ Professor, Department of OBG, DR BSA Medical College \& Hospital, Rohini, Delhi \\ Corresponding Author
}

Dr Chhavi

Senior Resident, Department of OBG, DR BSA Medical College \& Hospital, Rohini, Delhi, India

\begin{abstract}
Background: The incidence of Jaundice in pregnancy is 3\% to 5\%. The causes of jaundice in pregnancy can be coincidental liver disease, underlying chronic disease and condition related to pregnancy. Management of pregnant women with jaundice is very challenging because accurate diagnosis sometimes is very difficult and delay in management can be life threatening.

Objectives: The aim of the study was to evaluate the etiology of the jaundice among pregnant women, their management and outcome.

Methodology: A clinical audit was done in Department of Obstetrics and Gynaecology at Dr BSA Medical College and Hospital among pregnant women with jaundice who were admitted in the hospital over a period of four months.

Results: A total of 48 pregnant women with jaundice were admitted in hospital over the period of 4 months. All most all of them were in third trimester except three. Twenty four women were diagnosed as viral hepatitis with six women had hepatitis E. Ten women suffered from Intrahepatic cholestasis of pregnancy and 2 from obstructive jaundice (gallbladder stones and Common Bile Duct stones) and ten from hypertensive disorder in pregnancy and two had malaria. Almost half of women $(n=25)$ had preterm delivery and 12 women delivered by caesarean section (of these nine had preterm CS). Three women (7.14\%) had maternal mortality. All the three mortality belonged to hypertensive disorder in pregnancy and its associated complication. Perinatal mortality was $16.7 \%$ and all of them were preterm deliveries.

Conclusion: The disease is associated with high incidence of preterm labour. Main cause of maternal mortality was found to be hypertensive disorder in pregnancy and its sequel (coagulation failure, renal failure, septicaemia, hepatic failure) and main causative factor for perinatal mortality was prematurity and related problems.

Keywords: Pregnancy, Jaundice, Viral markers, Hepatic encephalopathy.
\end{abstract}

\section{Introduction}

Jaundice in pregnancy is one of the rare conditions associated with potential serious hazards for maternal and foetal health. Abnormallity of liver function in is $3 \%$ to $5 \%$ of pregnancies and it attributes to coincidental liver disease or chronic 
liver diseases. ${ }^{1}$ But there are liver diseases specific to pregnancy such as intrahepatic cholestasis of pregnancy, acute fatty liver of pregnancy, Preeclampsia, HELLP syndrome and Hyperemesis gravidarum. $^{2}$

Management of pregnant women with jaundice is very challenging as it different in pregnancy associated cause and other causes. Thus accurate diagnosis is the keystone for the treatment as sometime delay in it is life threatening for the mother as well as for foetus.

\section{Methods}

We did a clinical audit of pregnant women with jaundice admitted in department of Obstetrics and Gynaecology, Dr BSA Medical College \&Hospital, Rohini. The study was conducted over a period of 4 months. Detailed history was taken about the symptoms, their mode of onset, progression and duration of the disease and clinical examination was done. Patients were investigated for routine antenatal investigations as per institutional protocol along with serological tests, liver function test, coagulation profile and platelet count. All the patients were followed till delivery. Descriptive analysis was done to evaluate the cause of jaundice and their relation with maternal and foetal morbidity and mortality.

\section{Results}

There were 48 women who required admission in view of jaundice. Most of women were in the reproductive age group i.e. between 21 to 30years $(\mathrm{n}=41)$. Almost $83.7 \%(\mathrm{n}=41)$ women belong to middle class and $16 \%(\mathrm{n}=7)$ belong to lower class according to modified Kuppuswamy's socioeconomic status scale. ${ }^{3}$ Fifty eight percent $(n=28)$ of women were multigravida. Only $7 \%(n=4)$ of women were using methods to purify the drinking water. Most of women $(93 \%, n=45)$ were in third trimester and only 7\% (n=3) women were in second trimester. None of women were in first trimester.
Table 1 Etiology of jaundice

\begin{tabular}{|l|c|c|}
\hline Etiology & $\begin{array}{c}\text { No. of women } \\
(\mathrm{n}=48)\end{array}$ & $\begin{array}{c}\text { Percentage } \\
(\%)\end{array}$ \\
\hline $\begin{array}{l}\text { Intra hepatic cholestasis } \\
\text { of pregnancy }\end{array}$ & 10 & 20.8 \\
\hline $\begin{array}{l}\text { Hypertensive disorder } \\
\text { of pregnancy }\end{array}$ & 10 & 20.8 \\
\hline Hepatitis & 24 & 50 \\
Hepatitis A & 7 & 14.6 \\
Hepatitis B & 6 & 12.5 \\
Hepatitis C & 4 & 8.3 \\
Hepatitis E & 5 & 10.4 \\
Hepatitis B and C & 1 & 2.1 \\
Hepatitis A and E & 1 & 2.1 \\
\hline Malaria & 2 & 4.2 \\
\hline Obstructive jaundice & 2 & 4.2 \\
\hline
\end{tabular}

Major cause of jaundice in our study was viral hepatitis. Twenty four women (50\%) were diagnosed as viral hepatitis (Seven women had Hepatitis A, six had Hepatitis B, four had hepatitis $\mathrm{C}$ and five women had Hepatitis E). Ten women (20.8\%) were diagnosed to have hypertensive disorder in pregnancy with Jaundice, ten women (20.8\%) suffered from Intrahepatic cholestasis of pregnancy and two women (4.2\%) had obstructive jaundice (gallbladder stones and Common Bile Duct stones).

Thirty women $(62.5 \%)$ had serum bilirubin level less than $5 \mathrm{mg} \%$ and twelve women $(25 \%)$ had serum bilirubilin level between 5-10 mg\%.

All the women in study group had delivered. A total of 36 women $(75 \%)$ had vaginal delivery, out of which twenty five $(52.1 \%)$ had gone into spontaneous labour. All the women in second trimester underwent spontaneous labour. Sixteen women $(33.3 \%)$ were induced in view of uncontrolled symptoms of hypertensive disorders of pregnancy, intrauterine foetal demise, postdated pregnancy and abnormal biophysical profile. A total of 12 caesarean sections $(25 \%)$ were done in which 5 women were directly taken for caesarean section while the rest were due to failed induction.

Table 2 Mode of delivery

\begin{tabular}{|l|c|c|}
\hline Mode of delivery & $\begin{array}{c}\text { Number of } \\
\text { women }(\mathrm{n}=48)\end{array}$ & $\begin{array}{c}\text { Percentage } \\
(\%)\end{array}$ \\
\hline Vaginal & 36 & 75 \\
Spontaneous labour & 25 & 52.1 \\
Induced labour & 11 & 2.1 \\
\hline Caesarean Section & 12 & 25 \\
\hline
\end{tabular}


Maternal mortality was seen in 3 out of $48(6 \%)$ patients. The cause of maternal death in all three women were complications related to hypertensive disorders of pregnancy (two patients had eclampsia and related complications and third patient had HELLP Syndrome).

In regard to the neonatal outcome, more than half of the babies born to mothers with jaundice were preterm $(\mathrm{n}=25,52.1 \%)$. Nursery admission was in $27 \%(n=13)$ of neonates in which nine were preterm. Seven neonates (14.6\%) were still birth or expired in nursery. There were $22.9 \%(n=11)$ of neonatal with weight of less than two kilograms.

Table 3: Depicting Neonatal outcome in women with jaundice in Pregnancy

\begin{tabular}{|c|c|c|}
\hline Foetal outcome & $\begin{array}{c}\text { Number of } \\
\text { neonates }\end{array}$ & $\begin{array}{c}\text { Percentage } \\
(\%)\end{array}$ \\
\hline 1. Preterm & 25 & 52.1 \\
\hline Nursery admission & 13 & 27.1 \\
\hline Still birth/Neonatal death & 7 & 14.6 \\
\hline 2. Term & 23 & 47.9 \\
\hline Nursery admission & 4 & 8.3 \\
\hline Still birth /Neonatal death & 0 & 0 \\
\hline
\end{tabular}

\section{Discussion}

Liver diseases in pregnancy may or may not be specifically associated with the pregnancy. But whatever is the cause of the disease, it had potential effect on the maternal and foetal health. ${ }^{4,5}$

Condition specifically associated with pregnancy like preeclampsia and associated conditions, cholestasis of jaundice and acute fatty liver of pregnancy generally require termination of pregnancy irrespective of the period of gestation. It is also associated with neonatal morbidity and mortality due to prematurity and fetal growth restriction. Whereas conditions which is not directly associated with pregnancy such as viral hepatitis, jaundice due to infective pathology (dengue, malaria) and obstructive jaundice require conservative approach till the regression of the diseases. But in these cases, the women had a tendency to go into spontaneous labor which eventually leads to morbidity and mortality of the new born. So identification of the cause of disease associated with jaundice with pregnancy is of utmost importance.
There were 48 women who required admission in view of jaundice during the study period. Most of the women were in the reproductive age group i.e. between 21 to 30 years $(n=41)$. Almost $83.7 \%$ $(n=41)$ women belong to middle class and $16 \%$ $(n=7)$ were from lower socio-economic status. Fifty eight percent of women were multigravida and rest were primigravida which is comparable to the study by Jyothi G S et al. ${ }^{6}$

Most of women (93\%) were in third trimester and only $7 \%$ women in second trimester. None of women were in first trimester. This may be due to not registering themselves in the hospital early in pregnancy as we have almost $80 \%$ of unbooked cases in our study group. More over the clinical presentation of jaundice in early pregnancy are nonspecific and may confuse with normal changes of pregnancy by the women.

There were $58.3 \% \quad(\mathrm{n}=28)$ of pregnant women who were suffering from the jaundice, not directly associated with pregnancy. Among these causes the most common being is acute viral hepatitis, similar to the trend seen in general population ${ }^{7}$.

Fifty percent $(n=28)$ of these women had viral Hepatitis, followed by Malaria and Obstetric jaundice which is coinciding with the finding of Ching et al, but less than the study by Satia MN et al $(62 \%)^{8,9}$

There were 20 women $(41.6 \%)$ who had jaundice associated with pregnancy, in which half of them were due to hypertensive disorders of pregnancy and half were with cholestasis of pregnancy, whereas the study by Mishra et al had 83\% women with jaundice related with pregnancy of which almost $98 \%$ of women had hypertensive disorder of pregnancy. ${ }^{10}$

Thirty one women $(62.5 \%)$ had serum bilirubin level less than $5 \mathrm{mg} \%$ and twelve women had serum bilirubin level between 5-10 $\mathrm{mg} \%$. Women with hepatitis and malaria were having higher serum bilirubin level with very high liver enzymes(more than 1000IU/L) where as women with hypertensive disorder of pregnancy had serum bilirubin less than $5 \mathrm{mg} \%$ with high level of 
liver enzymes. Cholestasis of pregnancy had high level of alkaline phosphates in all the cases.

$52 \%$ of women had spontaneous labour which is consistent with the results of other studies. ${ }^{11}$

Twelve women (25\%) were taken for Caesarean section whereas study by Jyothi et al LSCS were done in $44.47 \%$ of women. ${ }^{5}$

In the present study, maternal mortality is $6.25 \%$ whereas the range in other studies were from $5 \%$ to $21 \%$. $^{9,10,12}$

Hepatitis $\mathrm{E}$ is associated with significant maternal mortality. ${ }^{13}$ Inspite of $12.5 \%$ of women infected with Hepatitis E, none of them had mortality but the study by Satia et al had higher rate of mortality with high incidence of Hepatitis E (43.63\%) in their study population. ${ }^{9}$

All the mortality in our study is due to preeclampsia associated complications(that is two women had eclampsia with pulmonary edema with MODS and one had HELLP syndrome) which is similar to the study by Mishra et al. ${ }^{10}$

There were $85.41 \%$ of women who had live birth which is coinciding with the study by Jyothi et al. ${ }^{6}$ There were a total of $52 \%$ patients who had preterm delivery and $12.72 \%$ patientshad still births with two intrauterine deaths. All of them were preterm. This showed that prematurity is the main cause of fetal mortality. There was $41.2 \%$ intrauterine demise in study of Mishra et al, whereas we had only two IUD in our study group.This signify more severity of cases in Mishra et al.$^{10}$

Liver diseases significantly affected by pregnancy are hepatitis E. It has a more severe course during pregnancy, with frequent fulminant hepatitis. The maternal mortality rate can be up to $20 \%$ for an acute infection in third trimester with a high risk of foetal or neonatal morbidity. Luckily, none of our women had this type of sequel. Chronic hepatitis $\mathrm{B}$ and $\mathrm{C}$ do not significantly progress during pregnancy, but there is risk of vertical transmission to the neonate. This can be managed by proper care during pregnancy, delivery and giving immunization to the newborn.
ICP present with several fold increase in aminotransferase levels and mild hyperbilirubinemia. The maternal outcome is good, but there is increased incidence of meconium ileus, premature delivery, or stillbirth. In our study, there were two stillbirths with ICP whereas maternal outcome was normal.

Patients who present with mild preeclampsia at term have minimally increased mortality risk but risk of mortality increase in Eclampsia can be upto $20 \% .^{14}$

This was also signified in our study. HELLP syndrome is a medical emergency, with risk of both maternal and foetal mortality and delivery being the definitive therapy. We had lost both mother and the foetus with HELLP in our study.

Acute fatty liver of pregnancy is a rare but severe disease. None of women had this in our study group. We found neonatal morbidity as evidenced by NICU admission was $27.9 \%$ and neonatal mortality was $16.2 \%$ in all the groups which was due to prematurity. Thus, Jaundice can be fatal for both the mother and foetus, if not managed promptly.

\section{Conclusion}

Jaundice with pregnancy is a dangerous combination. It has high incidence in developing countries compared to developed countries and also causes vary from place to place. Prompt diagnosis and treatment plays a key role in saving both the mother and child. Multidisciplinary approach (obstetricians, physician, gastroenterologist and anaesthesiologist)and team work is important in the management of these patients.

\section{References}

1. Mitra AK, Patki PS, Mitra SK, et al. Liver disorders during pregnancy and their management. The Antiseptic. 2008;105 (4):193-6

2. Hay JE, et al. Liver disease in pregnancy. Hepatology. 2008 Mar;47(3):1067-76. 
3. D. Mishra, HP Singh etal. Kuppuswamy's socio-economic status scale-A revision. The Indian Journal of Pediatrics,2003 March; 70(30):273-274.

4. Almashhrawi AA, Ahmed KT, Rahman $\mathrm{RN}$ et al. Liver diseases in pregnancy: diseases not unique to pregnancy. World $\mathrm{J}$ Gastroenterol.2013; 19(43):7630-8.

5. Ahmed KT, Almashhrawi AA, Rahman $\mathrm{RN}$ et al. Liver diseases in pregnancy: Diseases unique to pregnancy. World $\mathrm{J}$ Gastroenterol.2013;Nov 21;19(43):763946.

6. Jyothi G.S.,Chakraborty A, Swarup A et al. A study of feto-maternal outcome of jaundice in pregnancy.Int $\mathbf{J}$ Reprod Contracept Obstet Gynecol. 2018 Jul;7(7):2628-2633

7. Acharya SK, Dasarathy S, Kumer TL et al.Fulminant hepatitis in a tropical population: clinical course, cause and early predictors of outcome. Hepatology. 1996;23 (6):1448-55

8. Ching LY, Barge N, Dalal AR. Study of jaundice in a tertiary care institution in India. Bombay Hospital J. 2011;53:181-3.

9. Satia MN et al. A study of feto-maternal outcome in cases of jaundice at a tertiary care centre. Int J Reprod Contracept Obstet Gynecol. 2016 Jul;5(7):2352-2357

10. Mishra N, Mishra VN, Thakur P. Study of Abnormal Liver Function Test during Pregnancy in a Tertiary Care Hospital in Chhattisgarh.The Journal of Obstetrics and Gynecology of India. Sept-Oct 2016;66 (S1):S129-S135.

11. Greeshma, et al.: Maternal and fetal outcome in jaundice complicating pregnancy. Journal of Dr. NTR University of Health Sciences 2014;3(4).
12. Singh K, Kumar $\mathrm{G}$ et al. Outcome and management of antenatal patients with jaundice in tertiary care centre of eastern India: a retrospective study.Int J Res Med Sci.2015Sept; 3(9):2402-2404.

13. Kumar A, Beniwal B, Kar P, et al. Hepatitis E in pregnancy. Obstet Gynecol Surv 60:7,2005

14. Walker JJ: Pre-Eclampsia. Lancet 356:1260,2000. 